\title{
IoT-Based Real-Time Monitoring System for Epidemic Diseases Patients: Design and Evaluation
}

\author{
https://doi.org/10.3991/ijoe.v17i01.18849
}

\author{
Abdullah W. Al-Mutairi, Kasim M. Al-Aubidy $\left.{ }^{(}{ }^{\circledR}\right)$,Fadwa N. Alhalaiqa \\ Philadelphia University, Amman, Jordan \\ kma@philadelphia.edu.jo
}

\begin{abstract}
Epidemic diseases patients need constant monitoring of their health, whether in the hospital or at home, and this requires great costs. The employment of information and communication technologies and artificial intelligence concepts helps reduce these costs. This paper introduces a real-time monitoring system for monitoring pneumonia patients that will allow doctors to monitor the health of their patients remotely through smartphones or internetconnected devices. To verify the proper functioning of this system, a real-time monitoring device was developed. A secure mechanism is designed to establish a wireless connection to the monitoring unit.
\end{abstract}

Keywords - Healthcare; Epidemic diseases patients; Pneumonia patients; Realtime patient monitoring

\section{Introduction}

The accelerated development and advances in Internet of Things (IoT), wireless sensor network, mobile technology, cloud computing, and better internet coverage changed the way healthcare is approached around the world [1-4]. Several studies have been conducted about use of technologies in enhancing health services; IoT is one of these technologies that applied to interconnect available resources of medical service in addition to provide valid, effective smart service in health care to variety of population e.g., remote health monitoring, fitness programs, elderly care and chronic diseases [5]. Rapid developments in computer and communication technologies have contributed greatly to the modern healthcare systems. These technologies offer innovative ways to treat health problems in medical centers and beyond. Currently, various mobile health apps are available in the market to facilitate various health issues. However, scientific research in this area is still limited and there is ample scope for scientific research to exploit the Internet of things in mobile healthcare applications [6]. IoT recently is started to use in smart rehabilitation to extend the health services outside hospitals to home, these services might include monitoring and connecting of all healthcare resources (e.g., rehabilitation center, physician, nurses, ambulance, etc) with patients [5,7]. Sensing technologies also is used to detect and measure many physiological parameters regarding the patients (e.g., heart rate, temperature, pulse oximeter. etc) which could reflect smart health devices which can monitor patients, 
maintain contacts with doctors, improve the performance of rehabilitation, etc. These devices could help physician to diagnose and recommend treatment plan [5,9]. Another form which could be used smart health system which could provide multidimensional monitoring and suggest basic treatment such as wearable devices [4]. IoT based health monitoring systems provide several benefits such as low latency, minimum response time, high mobility, enhanced service quality, location awareness and notification service itself at the edge of the network [1]. Internet of things-based health monitoring contributes to improving individual quality of life and safe time and resources [8].

\section{$1.1 \quad$ Related work}

Sood and Mahajan [1] proposed an IoT assisted health monitoring system to identify possibly infected users in an early phase of their illness so that the outbreak of a virus can be controlled. A fuzzy-based diagnose algorithm is used to identify the possibly infected users and immediately generate diagnostic and emergency alerts to users. It also generates warning alerts to government and healthcare agencies to control the outbreak of a virus in risk prone or infected regions. They outlined that social network analysis is used to represent the state of a virus outbreak. The outbreak role index is calculated from social network analysis graph which represents the probability of any user to receive or spread the infection. Hassan et al. [10] provide an up-to-date review of the latest methods and algorithms used to design a wearable sensor to monitor a patient in the event of an outbreak of dengue fever. Based on the review, this paper specifies the parameters used in dengue for analysis purposes. Finally, an IoT-based patient monitoring system that incorporates three different sensors has been proposed to further work with analytical tools for dengue prediction pattern.

Modern healthcare systems are able to apply artificial intelligence concepts to the vast amount of data produced by wearable sensor networks through a combination of cloud and IoT architectures to make. Greco and his colleagues [4] suggested the use of IoT solutions in healthcare monitoring, "starting from early health monitoring solutions from wearable sensors up to a discussion about the latest trends in fog/edge computing for smart health". Islam et.al proposes a smart healthcare system in an IoT environment that can monitor a patient's basic health markers in addition to room condition [11]. The proposed system contains a set of sensors used to capture data from a hospital environment with an acceptable error (less than 5\%). The patients 'status is transmitted through a portal to the medical staff, where they can process and analyze the patients' current situation. They concluded that "the developed prototype is well suited to the proven healthcare monitoring system effectiveness".

Gupta et. al [12] suggested an IoT-based healthcare device for patients suffering from obesity. The device relies on measuring a number of parameters and then transmits the data for remote monitoring to healthcare professionals. Doctors can follow the patient and examine his/her health trends according to the stored data to monitor any changes that may be a symptom of an unnoticed underlying health condition.

The unavailability of physicians, nurses and medical follow-up for patients was the cause of the death of critically ill patients. An IoT healthcare system is proposed to monitor human health and send notification to physicians immediately in an 
emergency. It takes body parameters such as temperature, humidity, pulse sensor, and body movement and is compared with those of the in-situ patient to track abnormal physiological parameters [13].

Abdellatif and Mohamed [14] propose an IoT-based platform that connects the patient and the doctor. A number of medical sensors are connected to a server using communication technologies such as Wi-Fi, Bluetooth or GSM. Doctors are able to review the measured data online and inform patients of appropriate treatment remotely. Wan et al. Al [15] offers a real-time IoT-based health monitoring system based on IoT technology. Several wearable sensors are used, including heart rate, body temperature, and blood pressure sensors. The primary advantage of this design is that the data collected from the sensors is sent directly to the cloud without the need for a smartphone.

\subsection{Problem definition}

Direct monitoring of epidemic disease patients is the major challenge that faces health sector. The frontline health care workers are liable to get infection. Additionally, as a result of shortage in health care professionals, particularly nurses, this highlights the need of using technology in healthcare monitoring during epidemic.

With absence of proper vaccination, the world has moved (some countries) to start living with epidemic viruses. Meanwhile, others conduct isolation precaution for patients in their homes due to the scarcity and lack of places in hospitals.

This confirms the need for remote monitoring systems specializing in respiratory viruses such as the COVID-19 pandemic, where each patient is monitored remotely with unique identifiers. Taking into consideration that the world is going through economic and financial crises, where the system must be at the lowest possible costs.

\subsection{Objectives and importance}

The research aims to use the concepts of internet of things and reverse engineering to design a real-time monitoring system epidemic disease patients. The main objectives include:

- Maintain abroad monitoring, assessment and intervention.

- Simple design, low cost, and reliable.

- Made by using available components.

- Can be manufactured quickly and easily.

- It does not cause any risk to the patient. 


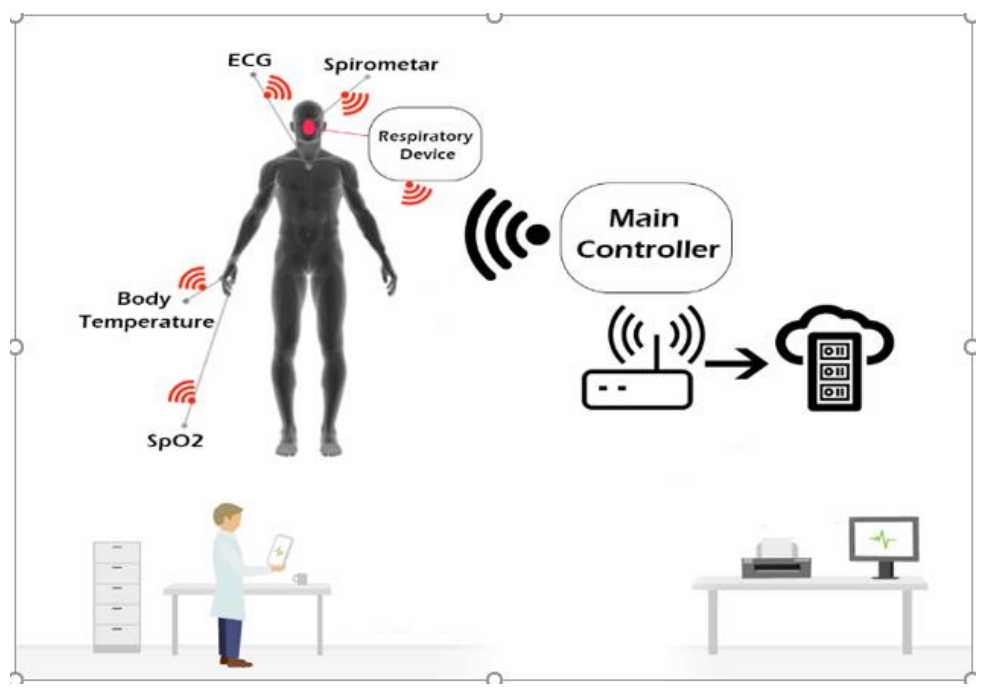

Fig. 1. Architecture for the proposed healthcare monitoring system.

The importance of this research work is to assist the patient with pneumonia who need 24 hours real-time monitoring. This can be achieved by transferring all patient parameters data to the specialist remotely, using the concepts of the Internet of Things and wireless sensor networks. In this case, the specialist will be able to monitor, evaluate, detect, maintain follow-up, enter and edit data in the database and intervene in emergency situations by controlling the oxygen flow to the patient.

\section{Proposed Scenario}

The proposed IoT-based healthcare monitoring system will record the patient parameters such as heart rate, body temperature, Oxygen saturation $\left(\mathrm{SpO}_{2}\right)$, heart's rhythm (ECG) and Lung functionality (Spirometer). All these data will be collected through set of sensors and data acquisition unit then will be sent to the online web server. Figure 1 shows the proposed architecture for the healthcare monitoring system. The patient health's sign can be monitored from anywhere in the world over internet. The system can detect the emergency situation and patient deterioration level. Therefore, an alarm will be activated remotely. Additionally, an urgent button can be used by the patient on emergency to send online alarm, emails and SMS messages to the specialist and healthcare providers.

The architecture of the proposed system consists of three main units: set of sensors, a data acquisition unit and a database server.

- Set of sensors: A set of sensors are used depending on the patient situation.

- Data acquisition unit: An embedded microcontroller is used to scan several sensors according to the patient's health condition. This unit is connected directly to a WiFi 
module for wireless communication. Data is collected through the Wi-Fi network and then sent to the database.

- Database server: The scanned data collected through the data acquisition unit is sent over the $4 \mathrm{G}$ network to the server to be stored in the database In this case the authorized specialist or physician can access it through a smart phone or a computer connected to the internet.

\section{Sensors}

A set of sensors, as illustrated in Fig.1, are used including body temperature, Oxygen saturation $\left(\mathrm{SpO}_{2}\right)$, heart's rhythm (ECG) and Lung functionality (Spirometer).

\subsection{Human body temperature sensor}

An infrared non-contact temperature sensor type (MLX90614) is used in this research to give freedom of movement for the patient and accuracy of reading, not like other sensors originally used to measure the atmosphere temperature and should be contact with the human body. It is serially connected to the ESP8266 WiFi module which allows temperature sensor to connect to a Wi-Fi network, as illustrated in Fig.2. The main features of this sensor are;

- Range for ambient temperature: -40 to $125^{\circ} \mathrm{C}$.

- Range for object temperature (non-contact): -70 to $380{ }^{\circ} \mathrm{C}$.

- Resolution: $0.02{ }^{\circ} \mathrm{C}$

- Accuracy: $0.5^{\circ} \mathrm{C}$ for $\left(0-50^{\circ} \mathrm{C}\right)$ both ambient and object.

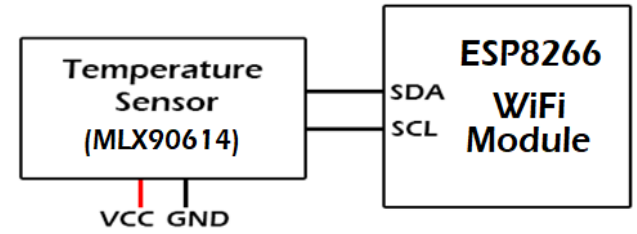

Fig. 2. Temperature sensor module.

\subsection{Breathing sensor}

The spirometers are used in the clinical setting to measure the amount of air inspired and expired by a person's lungs. A differential pressure sensor type (Honeywell ASDX Series Silicon) is used to calculate the flow rate and volume of air blown through the tube over a given time. As shown in Fig.3, the analog signal generated from the pressure sensor is interfaced to the analog input of the ESP8266 WiFi module to allow wireless communication with main controller. 


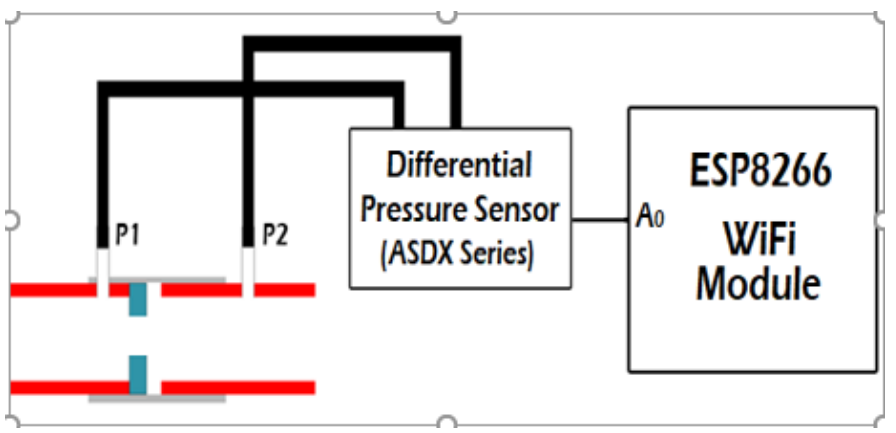

Fig. 3. Flow sensor module.

The diagnostic metrics for lung disease that the sensor will detect:

- Forced Vital Capacity (FVC): is the total volume (liters) of air that the subject can forcibly exhale in one breathe at least 6 seconds.

- Forced Expiratory Volume in one second (FEV1): is the volume of air that the subject exhales in the first second of a forced expiratory maneuver from 70 to 80 percent.

- Ratio (FEV1/FVC): indicates what percentage of the total FVC was expelled in the first second.

- Peak Expiratory Flow (PEF): The highest instantaneous airflow rate in liters per second, measured during the FVC maneuver.

- Total Lung Capacity (TLC): is defined as the maximum amount of air that the subject can breathe out after the deepest inspiration, whether or not the air was exhaled forcefully.

\subsection{Blood oxygen saturation sensor}

Blood oxygen level $\left(\mathrm{SpO}_{2}\right)$ is a measure of how much Oxygen the red blood cells are carrying. The body closely regulates your blood Oxygen level. Maintaining the precise balance of Oxygen-saturated blood is vital to the human health. People with chronic health conditions may need to monitor their blood oxygen level. This includes respiratory (e.g., pneumonia, chronic obstructive pulmonary disease asthma) and heart disease (Cardiomyopathy, congestive heart failure). In addition, COVID-19 is a disease caused by the SARS-CoV-2 virus that primarily attacks a person's respiratory system. So, the pulse Oximeter can assist to get accurate information about Oxygen level in the blood which mainly reflects the respiratory and cardiac condition of the patient.

In this research, an integrated pulse Oximeter monitor biosensor module type (MAX30102) is used. It includes internal LEDs, photo detectors, optical elements, and low-noise electronics with ambient light rejection. The selected sensor provides a complete system solution to ease the design-in process for mobile and wearable devices. The serial output data generated from this sensor is directly connected to the serial input of the ESP8266 WiFi module to allow wireless communication with main controller, as shown in Fig.4. The selected $\mathrm{SpO}_{2}$ sensor has the following features; 


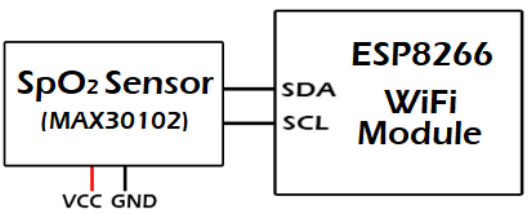

Fig. 4. Blood Oxygen saturation sensor module.

- Heart-rate monitor and pulse Oximeter biosensor in LED reflective solution.

- Ultra-low power operation for mobile devices.

- Fast data output capability.

- High sample rates.

\subsection{ECG sensor}

Medical studies indicate that heart disease is a major problem during the past decades, as many people die from some heart-related health problems. Therefore, the importance of analyzing and monitoring the ECG signal has increased in the initial stage for the purposes of diagnosis and prevention of this disease. One of the important feedback is the ECG signal in the initial stage so that the heart rate, rhythm and electrocardiograms can be detected and thus disease can be prevented. As illustrated in Fig.5, the analog output of the AD8232 ECG sensor module is connected directly to the Arduino Nano microcontroller, which is connected serially with the ESP8266 WiFi module for wireless communication with the main controller.

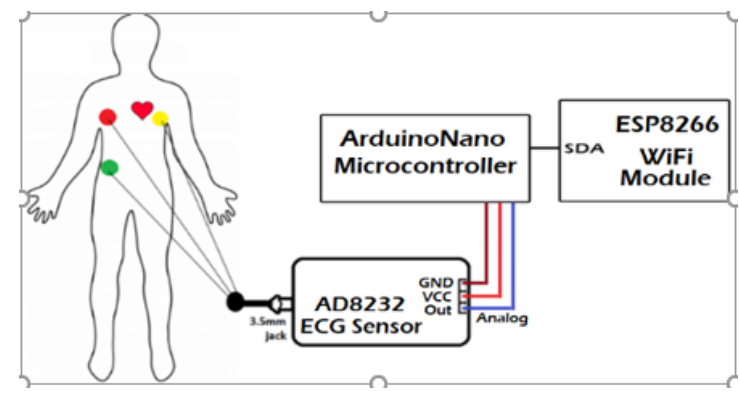

Fig. 5. The ECG sensor module.

\section{System Design}

The proposed system provides design of IoT-based real-time healthcare monitoring system for a patient or group of patients. Figure 6 shows a general layout of the proposed system, in which four sensors were used to provide the main microcontroller with the patient's health parameters, and accordingly the main microcontroller controls the ventilator and CPR devices. 


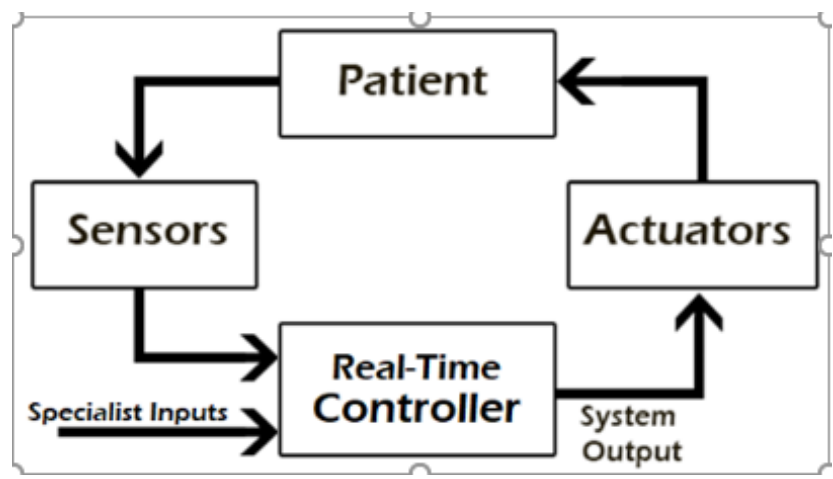

Fig. 6. General layout of the proposed monitoring system.

In the abnormal cases the medic or specialize only who will take the action such as control the ventilator device. The patients with respiratory problems as a result of an epidemic infection were kept in isolation room, the system will connect them to all health signs (heart rate, respire...etc) that will be taken remotely during that the oxygen supply $(3-5 \mathrm{l} / \mathrm{m})$ will be given according to their needs. In addition, spirometery devices will be used. All these actions will be applied by physician. In case of deterioration of patient signs (e.g. decrease heart rate less than 60, decrease $\mathrm{O}_{2}$ less than 75 ...etc), the medical team will take the required action such as connecting and setting the mechanical ventilator device.

The priority is for the doctor's decision. If the doctor or specialist applies any action, the system will consider it until it is changed by the doctor again. Figure 7 shows the main units of the monitoring system. The $\mathrm{O}_{2}$ will be one value between $3 \mathrm{l} / \mathrm{m}$ to $5 \mathrm{ll} / \mathrm{m}$, as shown in the table (1), the feedback and control for the ventilator device by control the breathing rate and tidal volume.

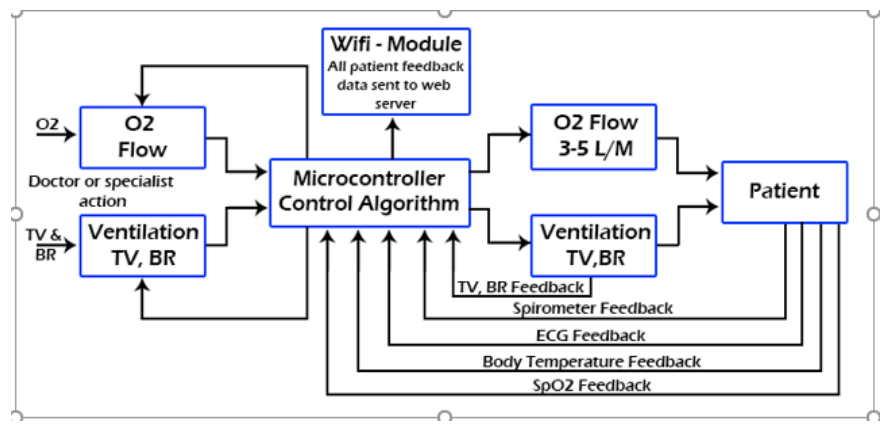

Fig. 7. Main elements of the proposed monitoring system.

\subsection{Hardware design}

The system consists of two main parts, as shown in the Fig.8; the patient sensors, and the main control unit. The patient sensors part consists of four wireless sensor nodes, while the main control unit contains the controller of the respiratory system. 


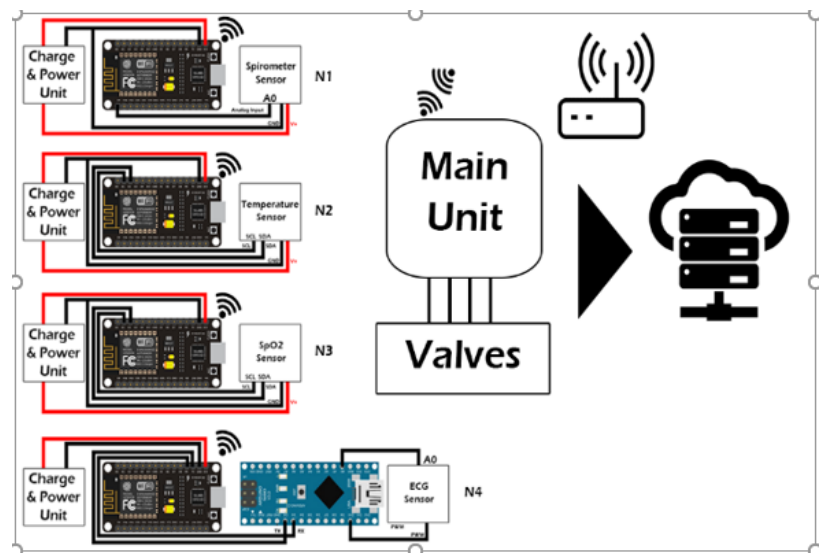

Fig. 8. Elements of the hardware design.

a) Patient sensors unit: In the system each sensor works wirelessly with rechargeable battery, the life time of each battery (5-9 hours) which is allow to move the patient from area to other, and can be used in the places not have any source of electricity power. Each unit has charging regulator module (TP4056) connected to the battery with voltage regulator (MCP1700-3302E) as illustrated in the Fig.9.

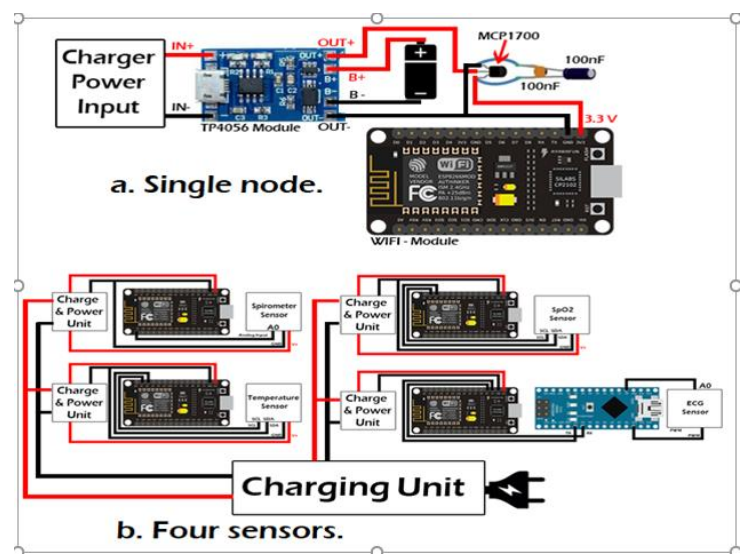

Fig. 9. Hardware design of patient sensors unit. 


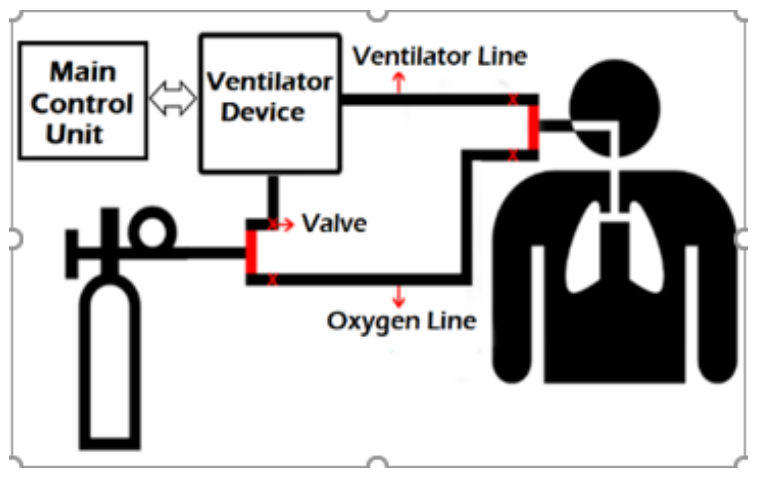

Fig. 10.Oxygen control layout.

b) Main control unit: The main control unit takes all the feedback signals from the patient sensors through a wireless sensor network, and sends the received data to a webhosting server. The respiratory system is controlled directly by the main unit. It allows the physician to provide Oxygen $3-5 \mathrm{l} / \mathrm{m}$ to the patient or to use the ventilator device if the case is needed, as shown in the Fig.10. If the patient is able to breathe and needs additional oxygen assistance, the control unit will allow oxygen flow of 3 $1 / \mathrm{m}$ for a moderate patient, and $5 \mathrm{l} / \mathrm{m}$ for a severe patient upon doctor's decision, see table (1).

For very sever patients (O2 sat less than 75 , heart rate less than $60 \mathrm{~b} / \mathrm{m}$, respiratory rate less than $10 \mathrm{c} / \mathrm{m})$ : the cardiopulmonary resuscitation $(\mathrm{CPR})$ and mechanical ventilator are needed.

Table 1. Machine action with abnormal parameters values.

\begin{tabular}{|l|c|c|c|c|}
\hline \multicolumn{1}{|c|}{ Parameters } & Normal & \multicolumn{3}{c|}{ Not Normal } \\
\hline Pulse $(\mathrm{b} / \mathrm{m})$ & $60-100$ & $<60$ & $>100$ & 60 to 100 \\
\hline Respiratory rate $(\mathrm{cycle} / \mathrm{min})$ & $12-24$ & $<12$ & $>24$ & 12 to 24 \\
\hline Temperature $\left({ }^{\circ} \mathrm{C}\right)$ & 37 & $<36$ & $>37.5$ & 36 to 37.5 \\
\hline $\mathrm{O}_{2}$ saturation & $95-100$ & $<90$ & $<90$ & $<90$ \\
\hline Action & $\mathrm{O}_{2}$ flow meter 3-5 l/m until the specialized reach the patient. \\
\hline
\end{tabular}

\subsection{Software design}

The embedded software of the implemented systems consists of set of programs to deal with hardware design and communicate with several nodes.

\section{a) Spirometer unit:}

The software steps, shown in Fig.11, are required to calculate the volume, these include: 
- Read in the analog signal from the sensor.

- Convert the measured signal into pressure parameter.

- Calculate the mass flow from the pressure parameter according to the sensor characteristics.

- Compute the volume by converting the mass flow to volumetric flow.

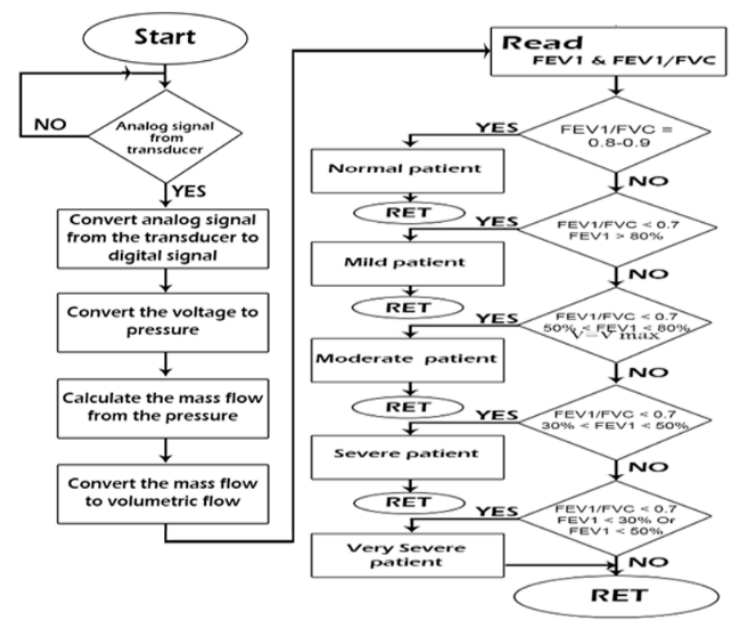

Fig. 11.Software flowchart for Spirometer unit.

The primary metrics used for diagnosing pulmonary illnesses are the forced vital capacity (FVC) and the forced expiratory volume in 1 second (FEV1). The main microcontroller computes the expected values of FEV1 based on the following regression equations [13] for males and females.

- For males under the age of 20 years

$\left(0.004477 \times\right.$ age $\left.^{2}\right)-(0.04106 \times$ age $)+\left(0.00014098 \times\right.$ height $\left.^{2}\right)-0.7453$

- For males over the age of 20 years:

$\left(-0.000172 \times\right.$ age $\left.^{2}\right)-(0.01303 \times a g e)+\left(0.00014098 \times\right.$ height $\left.^{2}\right)+0.5536$

- For females under the age of 18 years:

$(0.06537 \times$ age $)+\left(0.00011496 \times\right.$ height $\left.^{2}\right)-0.8710$

- For females over the age of 18 years:

$\left(-0.000194 \times\right.$ age $\left.^{2}\right)-(0.00361 \times$ age $)+\left(0.00011496 \times\right.$ height $\left.^{2}\right)+0.4333$

The expected values of FVC for males can be calculated by:

- For age less than 20 years:

$\left(0.010133 \times a g e^{2}\right)-(0.20415 \times a g e)+\left(0.00018642 \times\right.$ height $\left.^{2}\right)-0.2584$

- For males over the age of 20 years:

$\left(-0.000269 \times\right.$ age $\left.^{2}\right)+(0.00064 \times$ age $)+\left(0.00018642 \times\right.$ height $\left.^{2}\right)-0.1933$

While the expected values of FVC for females can be calculated by:

- For age less than 18 years: 
$(0.05916 \times$ age $)+\left(0.00014815 \times\right.$ height $\left.^{2}\right)-1.2082$

- For females over the age of 18 :

$\left(-0.000382 \times\right.$ age $\left.^{2}\right)+(0.01870 \times$ age $)+\left(0.00014815 \times\right.$ height $\left.^{2}\right)-0.3560$

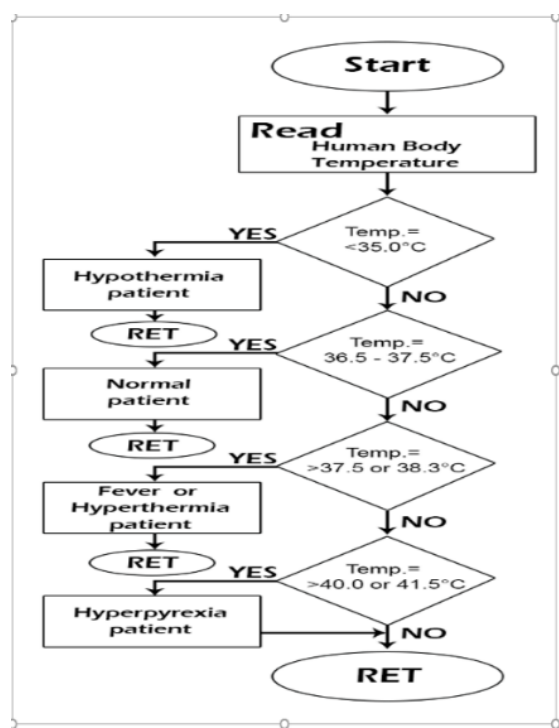

Fig. 12.Software flowchart for human body temperature unit.

The peak expiratory flow rate (PEFR) is also useful in the diagnosis of some illnesses [17], and can be calculated as:

- For males: e $(0.376 \ln ($ age $)-0.012($ age $)-(58.5 /$ height $)+5.63)$

- For females: e $(0.544 \ln ($ age $)-0.051($ age $)-(74.7 /$ height $)+5.48)$

\section{b) Human body temperature unit:}

Room temperatures range between $15^{\circ} \mathrm{C}$ and $19^{\circ} \mathrm{C}$ for adults $\left(18^{\circ} \mathrm{C}\right.$ and $21^{\circ} \mathrm{C}$ for babies and kids), and it is an essential role in the quality of our sleep. In fact, the sleep cycles are closely related to our internal heat distribution system, more commonly known as thermoregulation. If we sleep in an extremely hot or extremely cold environment, it interferes with the process of heat distribution in our bodies and creates uncomfortable conditions for sleep. Throughout the day, our body temperatures fluctuate between $2^{\circ} \mathrm{C}$ and $3^{\circ} \mathrm{C}$. When we lie in bed, our internal temperatures drop, signaling our brains that it is time to sleep.

\section{c) SpO2 unit:}

Figure 13 shows patient test flowchart for both normal and hypoxemia Oxygen levels based on the measurement of blood Oxygen ( $\mathrm{SpO} 2)$, as illustrated in Table (2). 


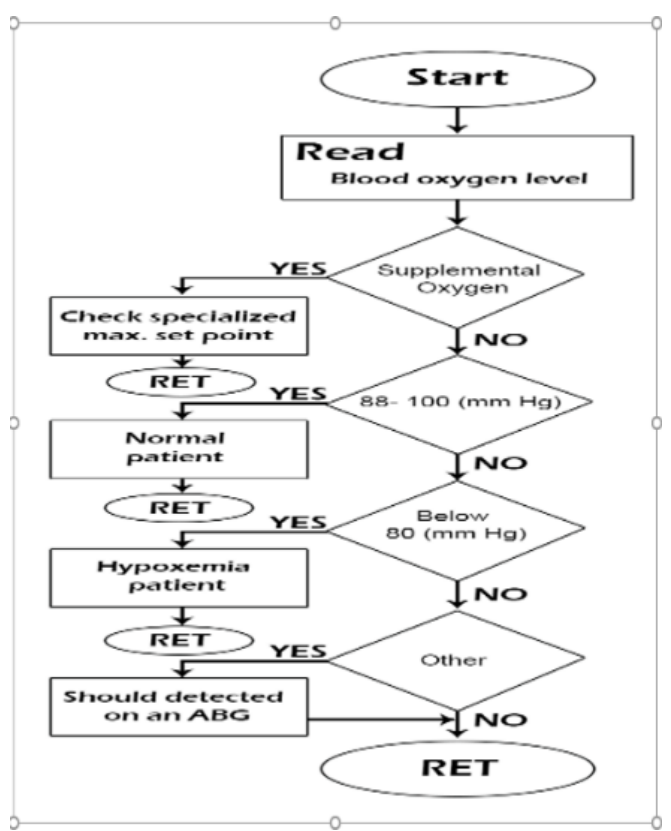

Fig. 13. Flowchart of $\mathrm{SpO}_{2}$ unit.

\section{d) ECG unit:}

From the ECG parameters shown in Fig.14, the analysis of heart rate variability (HRV) of the ECG signal can be implemented. According to the parameters changes comparing to the normal parameters given in Table 3, the system may predict which disease that the user potentially suffering from [18].

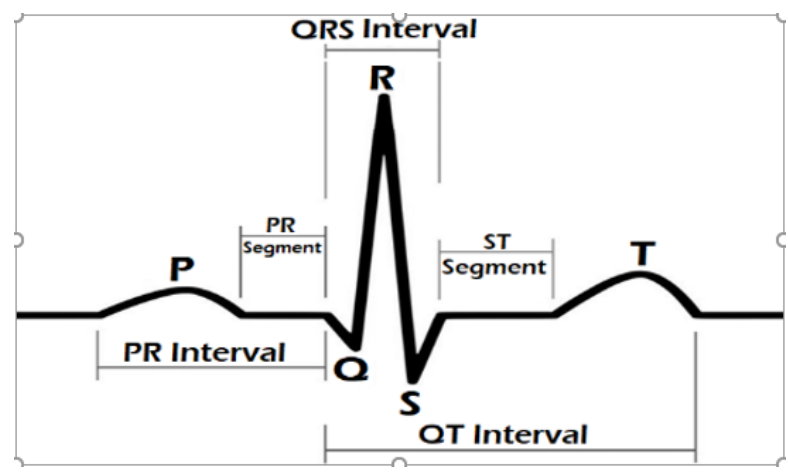

Fig. 14.Parameters of ECG signal. 
Table 2. Oxygen level test.

\begin{tabular}{|l|l|}
\hline \multicolumn{1}{|c|}{ Oxygen Level } & \multicolumn{1}{c|}{ SpO2 Result } \\
\hline $88-100(\mathrm{~mm} \mathrm{Hg})$ & Normal oxygen level \\
\hline Below $80(\mathrm{~mm} \mathrm{Hg})$ & Hypoxemia oxygen level \\
\hline If the breathing is assisted by supplemental Oxygen & Above normal oxygen level \\
\hline
\end{tabular}

Table 3. Normal ECG parameters.

\begin{tabular}{|l|c|}
\hline P Wave & $0.06-0.11<0.25$ PR \\
\hline Interval & $0.20-0.12$ \\
\hline PR Segment & 0.08 \\
\hline QRS Interval & $<0.120 .8-1.2$ \\
\hline ST Segment & 0.12 \\
\hline QT Interval & $0.36-0.44$ \\
\hline T Wave & 0.5 \\
\hline
\end{tabular}

\section{Wireless Communication}

The main unit is connected to the internet using ESP8266 WiFi module for wireless communication, as illustrated in Fig. 15. This module will start sending the data to the web hosting FTP using Linux server (Web Host Manager). All the data and patient monitoring readings will be stored in the database (MySQL). The specialist will interact with the data through a Graphical user interface (GUI) designed and programmed by using PHP language and CSS. The ESP8266 module will be used as client that makes an HTTP POST request to a PHP script to insert data (sensor readings, user input and device status) into a MySQL database.

The goal of this part is to visualize the readings from anywhere in the world by accessing our own server domain in the internet such as (www.philadelphia.edu.jo). The authorized specialist will directly update the set points of the ventilator to improve the patient's breathing situation.

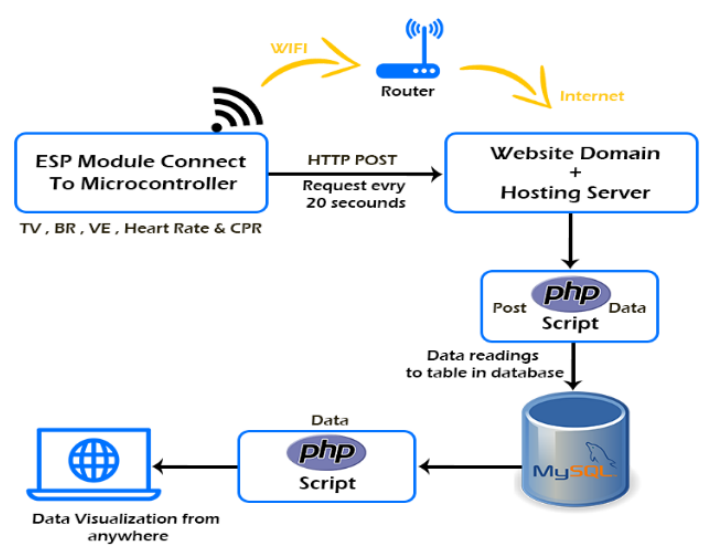


Fig. 15. High level overview for Remote connection.

\subsection{Dealing with the ventilator device}

In this step the main microcontroller will send the actual data of the patient to the doctor or specialize remotely, and this will be done by inserting this data into the website database (MySQL) and display it on the website page by using PHP programming language with CSS and HTML for the GUI.

\subsection{Creating and preparing the database (MySQL)}

After creating a hosting account and linking it to the domain name (www.philadelphia.edu.jo), it becomes possible to log into cPanel to create the database, username, password, and SQL table.

\subsection{PHP Script HTTP POST to insert data in the database}

This part is responsible for receiving incoming requests from the ESP8266 WiFi module and inserting the data into a MySQL database by creating a PHP code. The PHP file will be created in public html "is a directory on computers running Apache web servers that stores all HTML files and other web content to be viewed on the Internet".

\subsection{PHP script to display database content}

To display database contents into web page, another file should be created in the public_html by using different name, for example esp-data. php. The URL path will be (http://example-domain.com/esp-data.php).

\section{Results and Discussions}

The IoT healthcare monitoring prototype has been tested to make sure that all elements and components work properly, and to check its functionality, reliability and performance. The implemented prototype has set of sensors work wirelessly with the main unit which offers wireless communication between patient side and the health center through the internet. A $1000 \mathrm{mAh}$ battery was used to power the electronic circuits when running and testing the engineering model. The sensors consume around $150 \mathrm{mAh}$, so the average battery life is around 6 continuous working hours. The implemented database involves the medical history of every patient including collection of laboratory results, and assessment of a patient's health status. In addition, the implemented database involves the online data received from the patient's sensors including heartbeat rate, breathing rate, human body temperature, ECG signal, and blood pressure. A graphical user interface, has been designed to allow physicians and health center staff to monitor the extracted medical signals and parameters in real-time mode. 


\subsection{Spirometer unit test}

To test the accuracy of the spirometer unit, it should be connected to a breathing simulator. This breathing simulator is capable of simulating breathing patterns by individuals with varied pulmonary illnesses. It is usually used to test the accuracy of the spirometer unit. Since this simulation is not available, the "breathing simulator" will connect the spirometer to the ventilator to control breathing patterns through a software application. The obtained results from the implemented spirometery unit were compared with data obtained from a commercial digital spirometer "type SP10BT" to ensure the accuracy of the results. Figure 16 shows flow rate results for a 25 -year-old, female, non-smoker with restrictive lung disease. Restrictive lung disease is diagnosed when the ratio FEV1/FVC is greater than $80 \%$ and FVC value is less than $80 \%$. Figure 17 illustrates flow rate results for a smoker with chronic bronchitis.

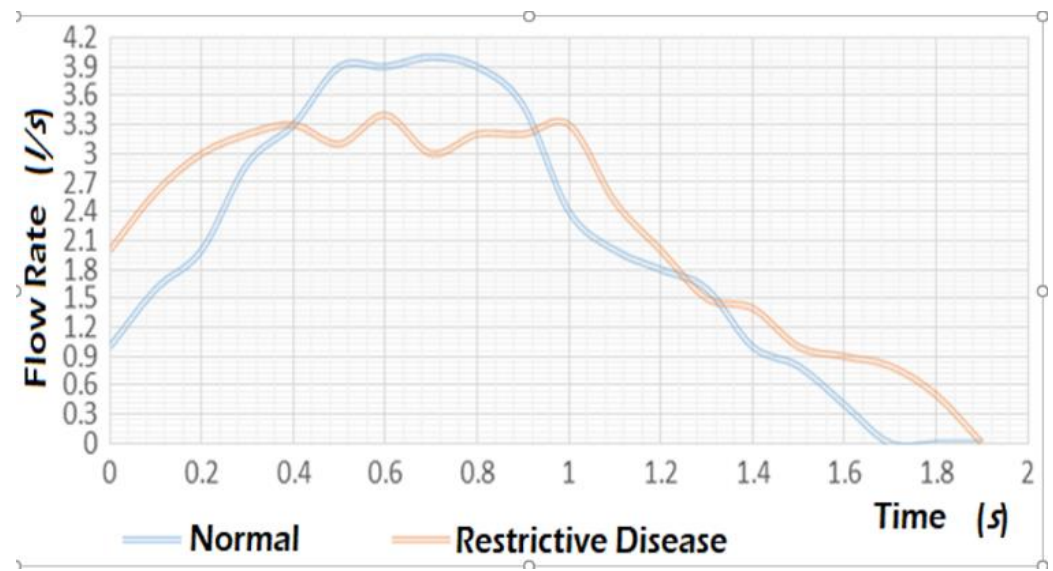

Fig. 16.Flow rate behavior for a non-smoker with restrictive lung disease.

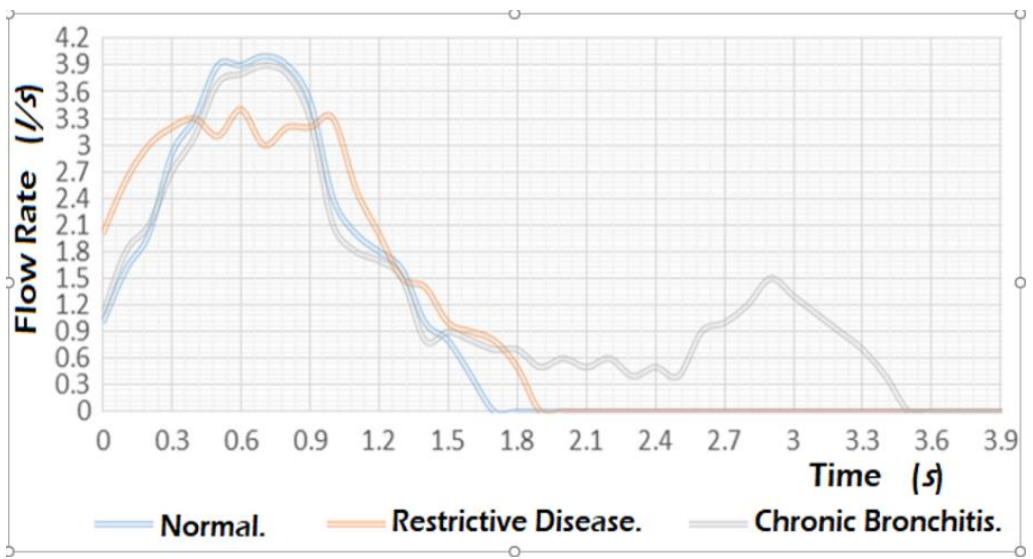

Fig. 17.Flow rate behavior for a smoker with chronic bronchitis. 


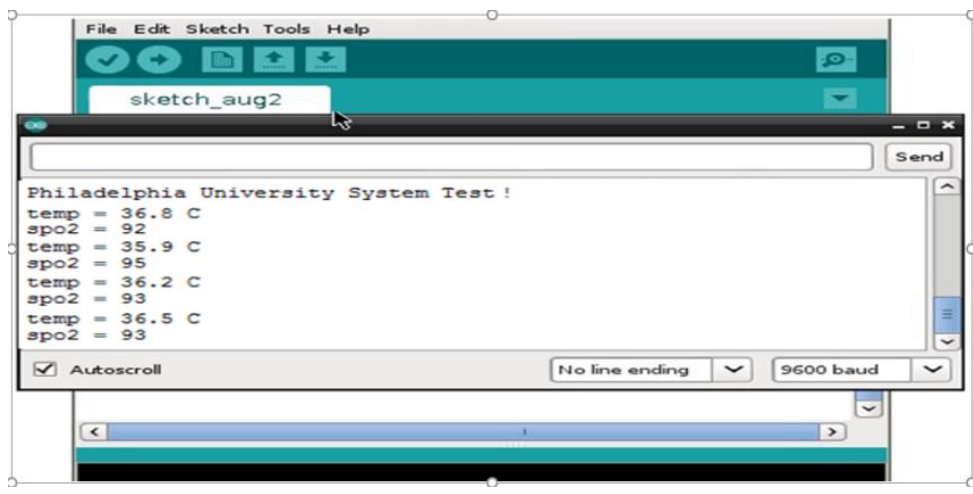

Fig. 18.Body temperature, $\mathrm{SpO}_{2}$ testing.

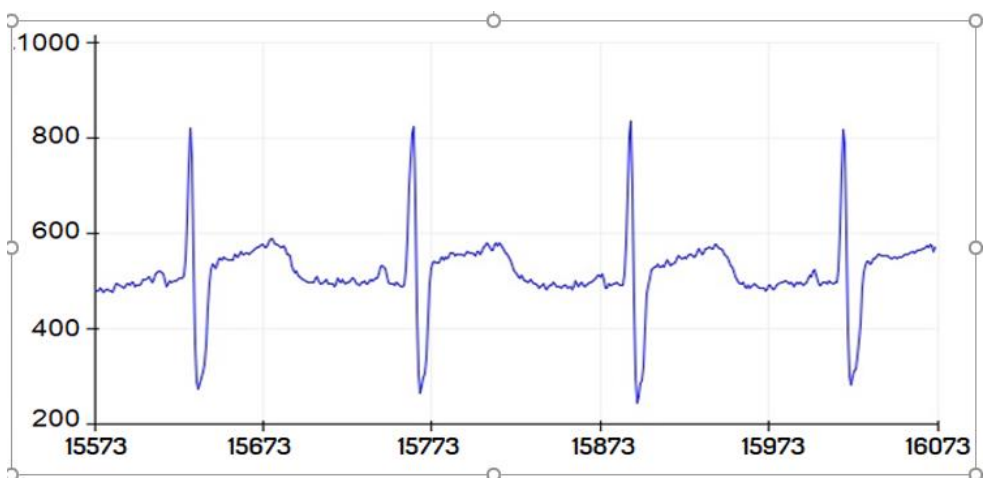

Fig. 19.ECG testing.

\subsection{Body temperature, $\mathrm{SpO} 2$ and ECG}

Sensors were connected to the microcontroller using serial data, and readings were displayed for each sensor to verify and fine-tune the sensors. Several tests were performed on the temperature sensor as the temperature readings change when the sensor is moved only a few centimeters from the body. It is essential to select the best position of the sensor to obtain accurate readings.

\subsection{Wireless connection test}

The wireless communication between several sensor modules, main unit and internet has been successfully tested. Note that the scanned data from sensors and calculated parameters are stored in the database and displayed on the web as a pointer (PHP) without a graphical user interface. The graphic user interface will be designed and programmed by specialized web hosting to read and display the data for the user and arrange the control panel (interact with the data), to have an account for each patient. Figure 20 illustrates patient data in the web server and includes human temperature, 
breathing rate, blood oxygen level and ECG parameters. The ECG is the height between $+300 /-200$ around the central value of about 500 .

\begin{tabular}{|c|c|c|c|c|c|}
\hline$\leftarrow$ & $\rightarrow \mathrm{C} \omega$ & (1) & & /philadelphia/ & … \\
\hline ID & Sensor & location & value & time & \\
\hline 01 & spirometer & $\mathrm{L} 1, \mathrm{~mm}$ & 1.1 & 2020-08-08 05:57:20 & \\
\hline 02 & temp & $\mathrm{L} 1, \mathrm{~mm}$ & 36.4 & 2020-08-08 05:57:21 & \\
\hline 03 & spo2 & $\mathrm{L} 1, \mathrm{~mm}$ & 89 & $2020-08-08$ 05:57:21 & \\
\hline 04 & ECG & $\mathrm{L} 1, \mathrm{~mm}$ & 292 & 2020-08-08 05:57:23 & \\
\hline 01 & spirometer & $\mathrm{L} 1, \mathrm{~mm}$ & 1 & 2020-08-08 05:59:09 & \\
\hline 02 & temp & $\mathrm{L} 1, \mathrm{~mm}$ & 35.8 & $2020-08-08$ 05:59:12 & \\
\hline 03 & spo2 & $\mathrm{L} 1, \mathrm{~mm}$ & 92 & $2020-08-08$ 05:59:14 & \\
\hline 04 & ECG & $\mathrm{L} 1, \mathrm{~mm}$ & 939 & 2020-08-08 05:59:14 & \\
\hline
\end{tabular}

Fig. 20.Patients data in the web server.

\section{Conclusion}

The research covered the design and implementation of a real-time healthcare monitoring system based on IoT for epidemic disease patients. This system can be used in both clinical and non-clinical settings (home, camp, etc.). The device can also be used as a tool for real-time monitoring and assisting in the healthcare of the elderly at home by taking advantage of the web capabilities and wireless sensors provided by this system to communicate directly with the specialist remotely. The experimental results of the several tests indicate the importance of using both wireless sensor networks and internet of things services to achieve high efficiency of the network and enable the doctor or specialist to follow the patient's condition and adjust the parameters of the device according to the immediate health status. The overall efficiency of the device can be improved through the use of advanced wireless modules and intelligent control methodology. The device can be further developed into continuous monitoring of different types of patients by adding a new type of sensor.

\section{$8 \quad$ References}

[1] Sood S. K., and Mahajan I. (2017). Wearable IoT sensor-based healthcare system for identifying and controlling chikungunya virus, Computers in Industry, No. 91, pp.33-44. https://doi.org/10.1016/j.compind.2017.05.006

[2] Valsalan P., Baomar T. A. B., and Baabood A. H. O. (2020). IoT based health monitoring system. Journal of Critical Reviews, Vol.7, No.4, pp.739-742.

[3] Al-Mutairi A. W. and Al-Aubidy K. M. (2020). Design and construction of a low cost portable cardiopulmonary resuscitation and ventilator device. $17^{\text {th }}$ IEEE Intr. Multi-Conf. on Systems, Signals, Devices (SSD2020), Tunisia, 20-23 July. 
[4] Greco L., Percannella G., Ritrovato P., Tortorella F., and Vento M. (2020). Trends in IoT based solutions for health care: moving AI to the edge. Pattern Recognition Letters, Vol.135, pp.346-353. https://doi.org/10.1016/j.patrec.2020.05.016

[5] Yin Y., Zeng Y., Chen X., and Fan Y. (2016). The internet of things in healthcare: an overview. Journal of Industrial Information Integration, Vol.1, March, pp.3-13.

[6] Jusoh S. (2017). A Survey on trend, opportunities and challenges of mHealth apps. International Journal of Interactive Mobile Technologies (iJIM). Vol. 11, No. 6, pp.73-85. https://doi.org/10.3991/ijim.v11i6.7265

[7] Floerkemeier C., Roduner C., and Lampe M. (2008). RFID application development with the Accada middleware platform. IEEE Systems Journal, Vol.1, No.2, January, pp.82-94. https://doi.org/10.1109/jsyst.2007.909778

[8] Islam S. M. R., Kwak D., Kabir M. H., Hossain M. and Kwak K. (2015). The Internet of things for health care: a comprehensive survey", IEEE Access, Vol.3, June, pp:678-708. https://doi.org/10.1109/access.2015.2437951

[9] Elaydi H. (2019). Personal Health Care System Using IOT. International Journal of Online and Biomedical Engineering (iJOE). Vol. 15, No. 7, pp.16-31. https://doi.org/10.3991/ ijoe.v15i07.10265

[10] Hassan N. H., Salwana E., Drus S. Md., Maarop N., Samy G. N., and Ahmad N. A. (2018). Proposed conceptual Iot-based patient monitoring sensor for predicting and controlling dengue. International Journal of Grid and Distributed Computing, Vol.11, No.4, pp.127-134. https://doi.org/10.14257/ijgdc.2018.11.4.11

[11] Islam Md. M., Rahaman A., and Islam Md. R. (2020). Development of smart healthcare monitoring system in IoT environment. Springer Nature Journal, SN Computer Science, 1:185. pp.1-11. https://doi.org/10.1007/s42979-020-00195-y

[12] Gupta D., Parikh A. and Swarnalatha R. (2020). Integrated healthcare monitoring device for obese adults using internet of things (IoT). International Journal of Electrical and Computer Engineering (IJECE) Vol.10, No.1, February, pp.1239-1247 https://doi.org/10.11591/ ijece.v10i2.pp1239-1247

[13] Senthilkumar S., Brindha K, and Kumar A. (2019). Patients health monitoring system using IoT. Indian Journal of Public Health Research and Development, April, Vol.10, No.4, pp:258-262. https://doi.org/10.5958/0976-5506.2019.00699.5

[14] Abdellatif M. M., and Mohamed W. (2020). Telemedicine: An IoT Based Remote Healthcare System. International Journal of Online and Biomedical Engineering (iJOE). Vol. 16, No. 6, pp.72-81. https://doi.org/10.3991/ijoe.v16i06.13651

[15] Wan J., Al-awlaqi M. A. A. H., Li M. S., O’Grady M., Gu X., Wang J., and Cao N. (2018). Wearable IoT enabled real-time health monitoring system. Journal on Wireless Communications and Networking, No.298, pp:4-10. https://doi.org/10.1186/s13638-0181308-x

[16] Hankinson J. L., Odencrantz J. R., and Fedan K. B. (1999). Spirometric reference values from a sample of the general U.S. population. American Journal of Respiratory and Critical Care Medicine, January, Vol.159, No.1, pp.179-87. https://doi.org/10.1164/ajrccm. $\underline{159.1 .9712108}$

[17] Radeos M. S. and Camargo, C. A. (2004). Predicted peak expiratory flow: differences across formulae in the literature. American Journal of Emergency Medicine, November, Vol.22, No.7, pp.516-521. https://doi.org/10.1016/j.ajem.2004.08.018

[18] Al-Aubidy K. M., Derbas A.M., and Al-Mutairi A. W. (2017). Real-time healthcare monitoring system using wireless sensor network. International Journal of Digital Signals and Smart Systems, Vol.1, No.1, January, pp.26-42. https://doi.org/10.1504/ ijdsss.2017.10008057 


\section{$9 \quad$ Authors}

Abdullah W. Al-Mutairi obtained his BSc degree in mechatronics engineering in 2016 from Philadelphia University, Jordan and his MSc degree in mechatronics engineering from Swiss German university Indonesia in 2019. His main areas of research are mechatronic systems design, embedded systems design, IoT applications.

Kasim M. Al-Aubidy received his BSc and MSc degrees in control and computer engineering from the University of Technology, Iraq in 1979 and 1982, respectively, and the $\mathrm{PhD}$ degree in real-time computing from the University of Liverpool, England in 1990. He is currently a professor and dean of the Faculty of Information Technology at Philadelphia University, Jordan. His research interests include fuzzy logic, neural networks, genetic algorithm and their real-time applications. He was the winner of Philadelphia Award for the best researcher in 2000. He is editor-in-chief of two international journals and a member of editorial board of international journals. He has coauthored 5 books, 3 chapters-in-books and published 94 papers on topics related to computer applications. Email: kma@philadelphia.edu.jo

Dr. Fadwa N. Alhalaiqa is associate professor of psychiatric / mental health and dean at nursing faculty of Philadelphia University, Jordan. She finished her PhD in Nursing from University of East Anglia UK, 2013. Dr. Alhalaiqa's research interests are health policy, adherence, mental health problems, chronic diseases and nursing sciences. She has more than 35 research papers that were published in high prestigious journals. Dr. Alhalaiqa is a treasurer of OWSD Jordan Chapter, board member of Psychological Sciences Association (PSA)/Jordan, and member of Cochrane hypertension group. She has more than $30 \mathrm{TV}$ shows and broadcasting news. Dr. Alhalaiqa is an active person in voluntary work in Jordan community.

Article submitted 2020-09-25. Resubmitted 2020-10-29. Final acceptance 2020-10-29. Final version published as submitted by the authors. 